\title{
An ultrastructural and immunocytochemical study of a renal carcinoma secreting inactive renin
}

\author{
GBM LINDOP, IAR MORE, BRENDA LECKIE* \\ From the University Department of Pathology and the *MRC Blood Pressure Unit, Western Infirmary, \\ Glasgow G11 6NT
}

SUMMARY This is a case report of a renal carcinoma which was secreting inactive renin. Using an antibody to human renin and the indirect immunoperoxidase technique, the renin-containing cells were localised within the tumour. These were found to be small granular cells situated in a perivascular position. The histological immunocytochemical and ultrastructural features of these cells are described.

It is now well known that malignant tumours may produce hormones. Sometimes the hormone which is produced by the tumour is in the form of a prohormone or a biologically inactive form. ${ }^{1}$ Inactive renin is normally present in human plasma ${ }^{2}$ and has been reported in the tumour and plasma in a case of nephroblastoma. ${ }^{3}$ We have studied a renal carcinoma which was secreting inactive renin. Using an antibody to pure human renin and the immunoperoxidase technique we have identified the cells within the tumour which contained immunoreactive renin. We report here the study of these cells by light and electron microscopy.

\section{Case report}

The patient was a 65 -year-old man who presented with mild hypertension $(180 / 110 \mathrm{~mm} \mathrm{Hg})$. He was found to have raised concentrations of plasma renin but normal plasma angiotensin II concentrations. This was due to the fact that most of the renin in the plasma was biologically inactive. After onset of haematuria he was found to have a tumour in the upper pole of his right kidney. The right kidney was removed and the tumour was found to contain high concentrations of inactive renin. After nephrectomy the plasma renin concentrations fell to normal. Six months after nephrectomy, plasma inactive renin again rose. A metastasis was found in a rib. This was treated by radiotherapy and excision, wherupon plasma renin concentrations fell to normal. Full details of the biochemical investigation of the renin-angiotensin system in this case are published elsewhere. ${ }^{4}$

Accepted for publication 6 December 1982

\section{Materials and methods}

\section{LIGHT MICROSCOPY}

Tissue from the tumour and from the kidney was fixed in neutral buffered formalin, embedded in paraffin wax and $4 \mu \mathrm{m}$ sections were used for histological stains. Adjacent sections were used for immunocytochemistry.

\section{ELECTRON MICROSCOPY}

Small pieces of the tumour were fixed in glutaraldehyde and post-fixed in osmium tetroxide. They were embedded in Araldite and sectioned on a LKB Ultratome I. The sections were double stained with uranyl acetate and lead citrate and examined on a Philips $301 \mathrm{G}$ electron microscope.

\section{IMMUNOCYTOCHEMISTRY \\ Renin antiserum}

Renin antiserum was prepared from pure human renin isolated from a juxtaglomerular cell tumour. The criteria of purity and the physicochemical characteristics of the renin isolated have been published. ${ }^{5}$ Antibodies to the purified renin were raised in rabbits and the affinity and specificity of the antibody have been carefully tested. ${ }^{6}$ This antibody to human renin has been used to detect renin by immunoperoxidase and immunofluorescence techniques in tissue sections of normal ${ }^{78}$ and pathologi$\mathrm{cal}^{79}$ kidneys and of a renin-secreting juxtaglomerular cell tumour. ${ }^{7}$ Human renin has been only recently purified and there was insufficient pure human renin available to perform adsorption tests with antibody which had been previously incubated 
with renin. The results of such adsorption tests with this antibody have already been published. ${ }^{7}$ These immunofluorescence and PAP studies confirmed the specificity of the immunochemical reaction.

\section{Staining techniques}

The paraffin-embedded sections were dewaxed with xylene then hydrated by passage through graded alcohols to distilled water. They were then rinsed with Tris-buffered saline (TBS) at $\mathrm{pH} 7.4$ and treated with pooled normal swine serum (diluted $1 / 5$ with TBS) for $10 \mathrm{~min}$. After draining off excess serum the slides were placed in a humidity box and the sections covered with rabbit anti-human renin serum diluted 1/1000 in Tris-buffered saline $\mathrm{pH} 7 \cdot 5$. After incubation at $4^{\circ} \mathrm{C}$ for $72 \mathrm{~h}$ the antibody was washed from the slides with TBS over $30 \mathrm{~min}$. The slides were rinsed in distilled water then washed in methanol.

Endogenous peroxidase was removed by immersing the sections in $0.5 \%$ hydrogen peroxide in methanol for $30 \mathrm{~min}$. This solution was washed off with tap water then distilled water and TBS. The slides were then treated with swine antirabbit immunoglobulin, diluted to $1 / 50$ in $1 / 25$ normal swine serum in TBS (NSS/TBS) and incubated for $30 \mathrm{~min}$ at room temperature. Slides were rinsed free of immunoglobulin by three washes of TBS. The antibody bridge was completed by treatment for $30 \mathrm{~min}$ in rabbit peroxidase-antiperoxidase (PAP) diluted $1 / 100$ in NSS/TBS. The slides were again washed with TBS and the antigen/antibody binding site visualised by incubating the slides with a diaminobenzidine (DAB)/hydrogen peroxide solution in TBS (pH 7.4) as used by Karnovsky and Graham. ${ }^{10}$ The slides were rinsed in TBS and tap water and counterstained with Mayer's haemalum before dehydration through graded alcohols and xylene before mounting in synthetic resin.

The renin-containing juxtaglomerular cells in the adjacent kidney provided internal positive controls as they were often present in the same section as the tumour. Negative controls were sections in which normal rabbit serum and pooled rabbit immunoglobulin were substituted for the anti-renin antibody. Both were also diluted to $1 / 1000$ in TBS.

To identify macrophages, sections were stained with $\alpha_{1}$-antichymotrypsin and antimuramidase (Dako Labs, UK). These sections were pretreated by incubation with $0.1 \%$ trypsin (Sigma) and $0.1 \%$ calcium chloride in TBS (pH 7.8) for $20 \mathrm{~min}$. They were then incubated with the antibodies for $30 \mathrm{~min}$ at room temperature. The $\alpha_{1}$-antichymotrypsin was used diluted to 1/50 and the antimuramidase was used at dilutions of $1 / 1500$ and $1 / 3000$. Both were diluted in a solution of TBS plus normal swine serum (Gibco, Europe) in a ratio of 25:1. Positive control sections containing abundant macrophages were included and negative control sections were incubated with normal rabbit immunoglobulin at the same dilution in TBS as the test antibodies.

\section{Results}

\section{KIDNEY SPECIMEN}

The nephrectomy specimen contained a $5 \mathrm{~cm}$ diameter tumour in the upper pole. On section, it appeared to be a typical renal cell carcinoma, yellow with areas of haemorrhage (Fig. 1). There was invasion of the surrounding kidney and the renal pelvis but the renal vein was free of tumour.

\section{LIGHT MICROSCOPY}

Paraffin sections showed the tumour to be uniform in appearance in the multiple blocks examined. It was composed of large polygonal clear cells grouped in linear, acinar and alveolar structures which were separated by a fine but richly vascular stroma (Figs. 3 and 4). The small nuclei had compact chromatin and inconspicuous nucleoli and the mitotic rate was very low. The histological appearances were those of a typical moderately well differentiated clear cell renal carcinoma.

\section{IMMUNOCYTOCHEMICAL FINDINGS}

Immunoperoxidase preparations stained with the antirenin antibody showed the presence of renin in juxtaglomerular cells in the kidney surrounding the

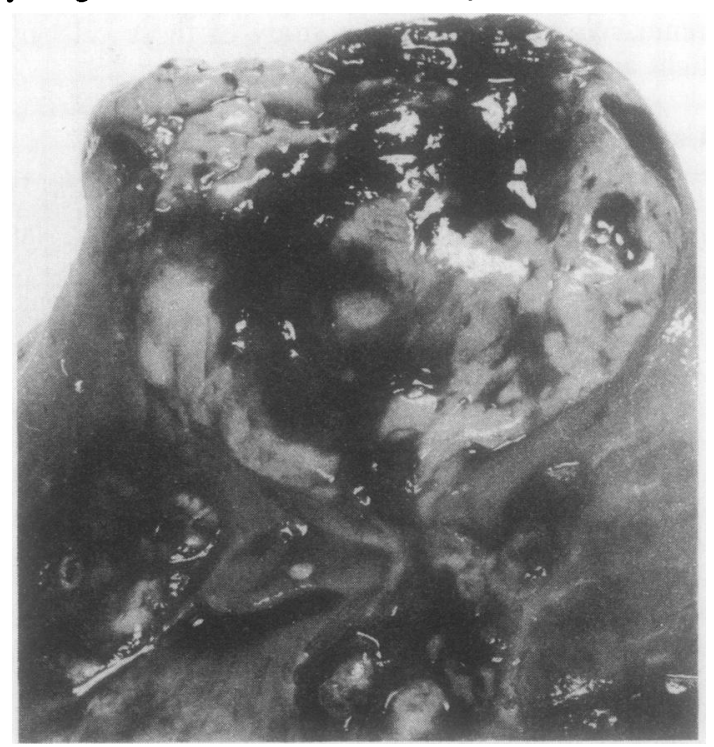

Fig. 1 Photograph of the tumour in the upper pole of the left kidney. There is extensive invasion of the surrounding kidney and the renal pelvis. Original magnification $\times 2$. 


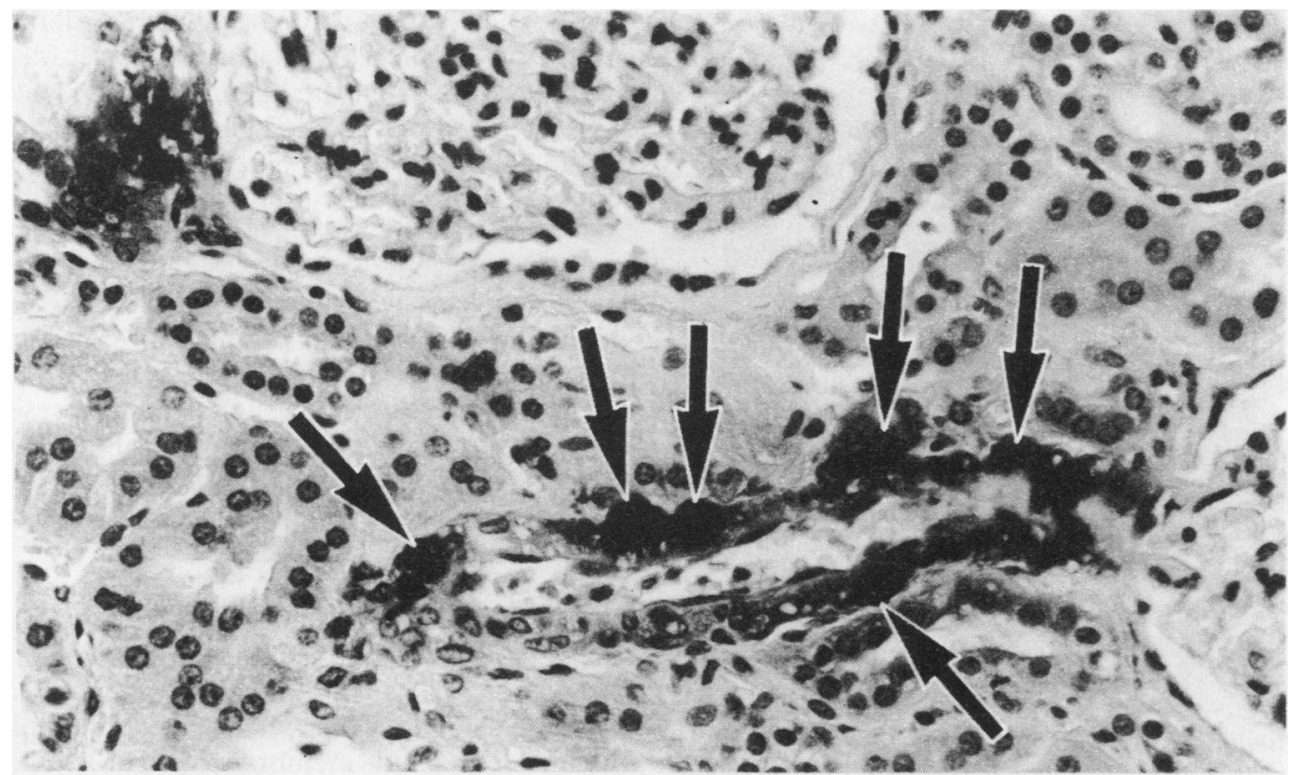

Fig. 2 Renin PAP preparation of kidney adjacent to the tumour showing two glomeruli with afferent arterioles, one of which shows hyperplasia of the renin-containing cells. The cells which appear to contain most renin (arrows) are external in situation. Original magnification $\times 100$.

tumour. In the areas of the kidney which were compressed by the tumour there was hyperplasia of the renin-secreting cells of the glomerular afferent arterioles. The cells which stained most strongly appeared to be externally situated on the arterioles (Fig. 2). There was negligible background staining.

There were many cells in the tumour which contained immunoreactive renin (Figs. 3 and 4). The large clear tumour cells were uniformly negative in multiple blocks of tumour examined. The renincontaining cells were much smaller and appeared to be in the stroma surrounding the groups of tumour cells. They were of variable shape and size but their situation was constant. Serial sections showed that they were always applied to the capillary and sinusoidal blood vessels within the tumour, apparently just external to the endothelium (Figs. 3 and 4). In some sections these cells appeared round; in others, they were fusiform with long dendritic processes containing immunoperoxidase-positive granules. The intensity of staining was usually lighter, but some cells were found which stained as densely as the normal juxtaglomerular cells in the adjacent kidney present in the same section. None of these cells showed cytological features of malignancy and mitotic figures were not identified. Sections stained with antibodies to muramidase and $\alpha_{1}$-antichymotrypsin confirmed the presence of a small population of macrophages. These were most apparent near areas of necrosis and haemorrhage

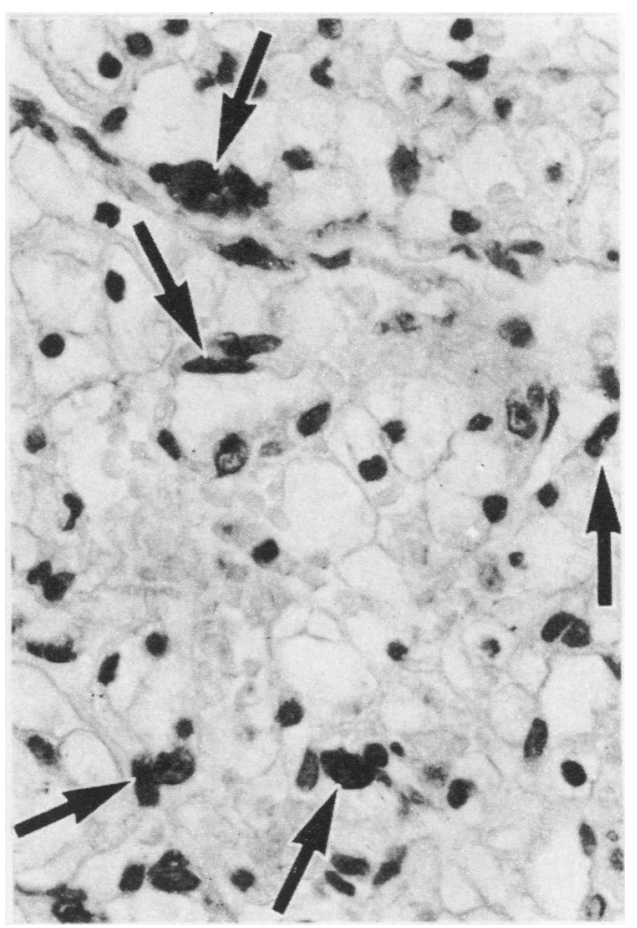

Fig. 3 Renin PAP preparation showing the typical morphology of a clear cell carcinoma. The clear tumour cells are uniformly negative while the positive cells (arrows) stain strongly. Original magnification $\times 250$. 


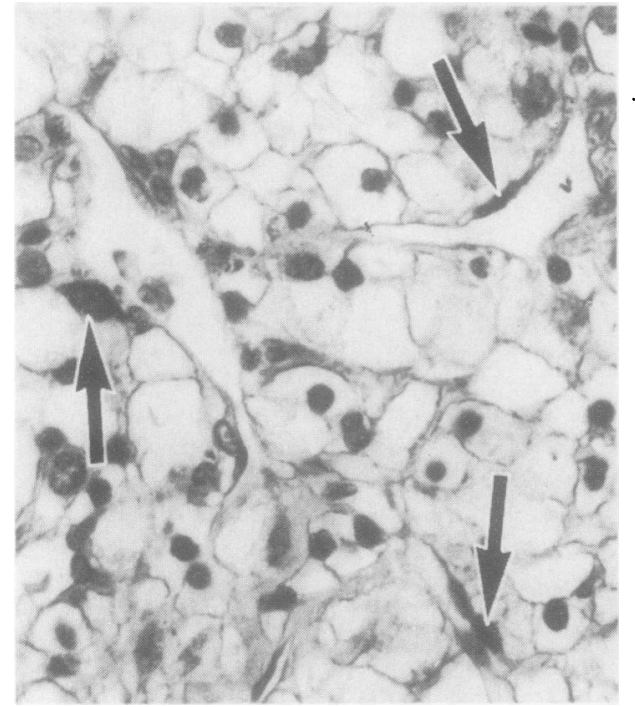

Fig. 4 Renin PAP preparation showing the relation of the positive cells (arrows) to the capillary and sinusoidal blood vessels. Original magnification $\times 250$. where they often contained haemosiderin. The brown stain of the DAB reaction product was easily distinguishable from the haemosiderin. Some renin PAP sections were counterstained by Perls' reaction and this contrasted the blue iron-containing macrophages with brown renin-containing cells. Sections stained by Giemsa and toluidine blue confirmed that there was a population of mast cells. These were clearly distinguishable from the perivascular cells which contained immunoreactive renin.

Sections stained with Bowie's stain, Wilson's stain, and PAS after diastase showed the presence of fine granules in the perivascular cells in the tumour, and confirmed the granularity of the juxtaglomerular cells in the kidney adjacent to the tumour.

\section{ELECTRON MICROSCOPY}

Fixation for electron microscopy was not ideal. The small granular cells were found singly in a perivascular position (Fig. 5) and although intimately associated with capillaries they were always external to the vascular basement membrane (Fig. 6). The cells were irregular in shape and contained abundant

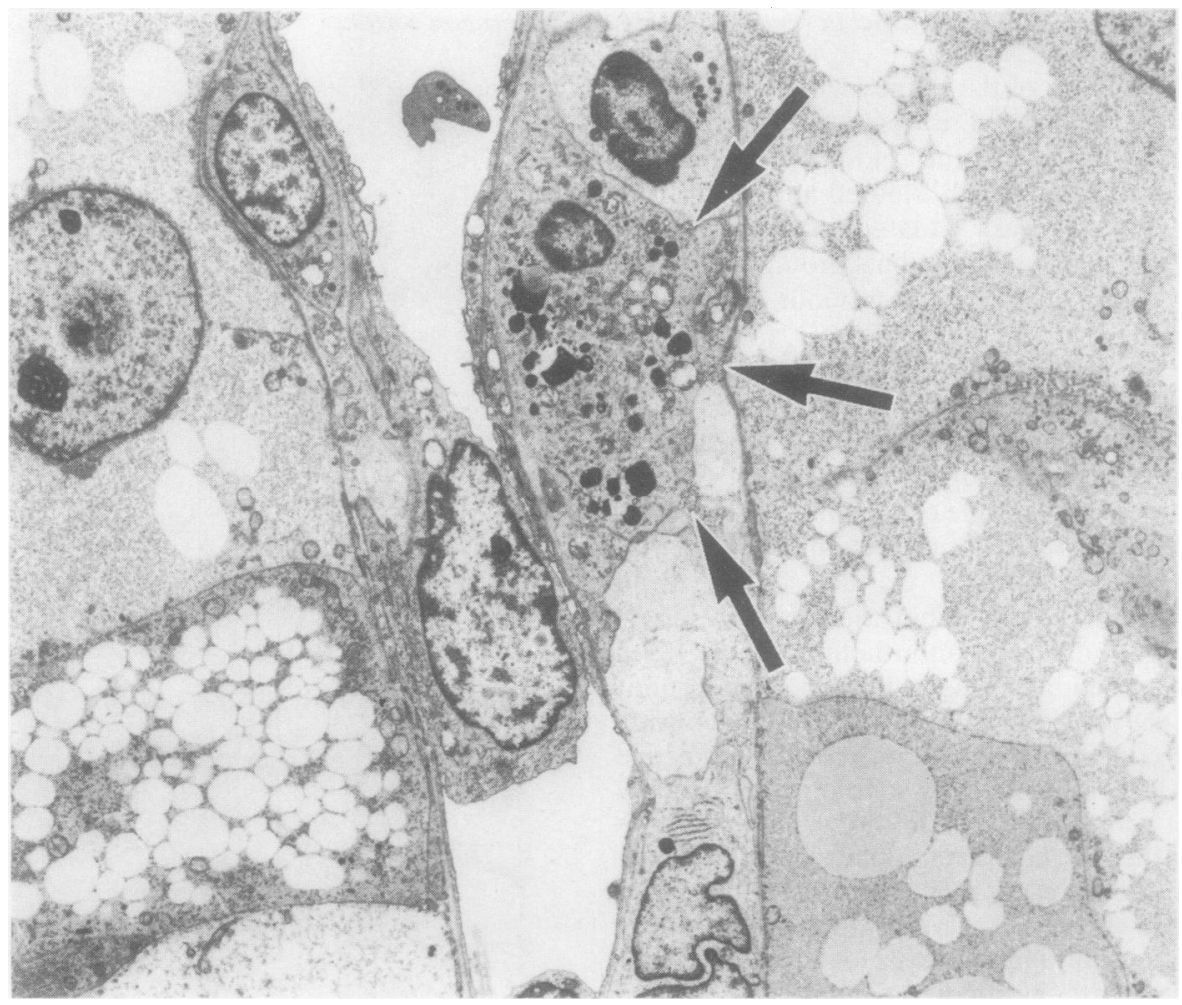

Fig. 5 Electron micrograph showing the typical ultrastructural features of a clear cell carcinoma, the tumour cells being filled with fat globules and glycogen. There is a small cell containing both polyhedral and rounded granules (arrowed) external to the basal lamina of the capillary. $\times 2925$. 


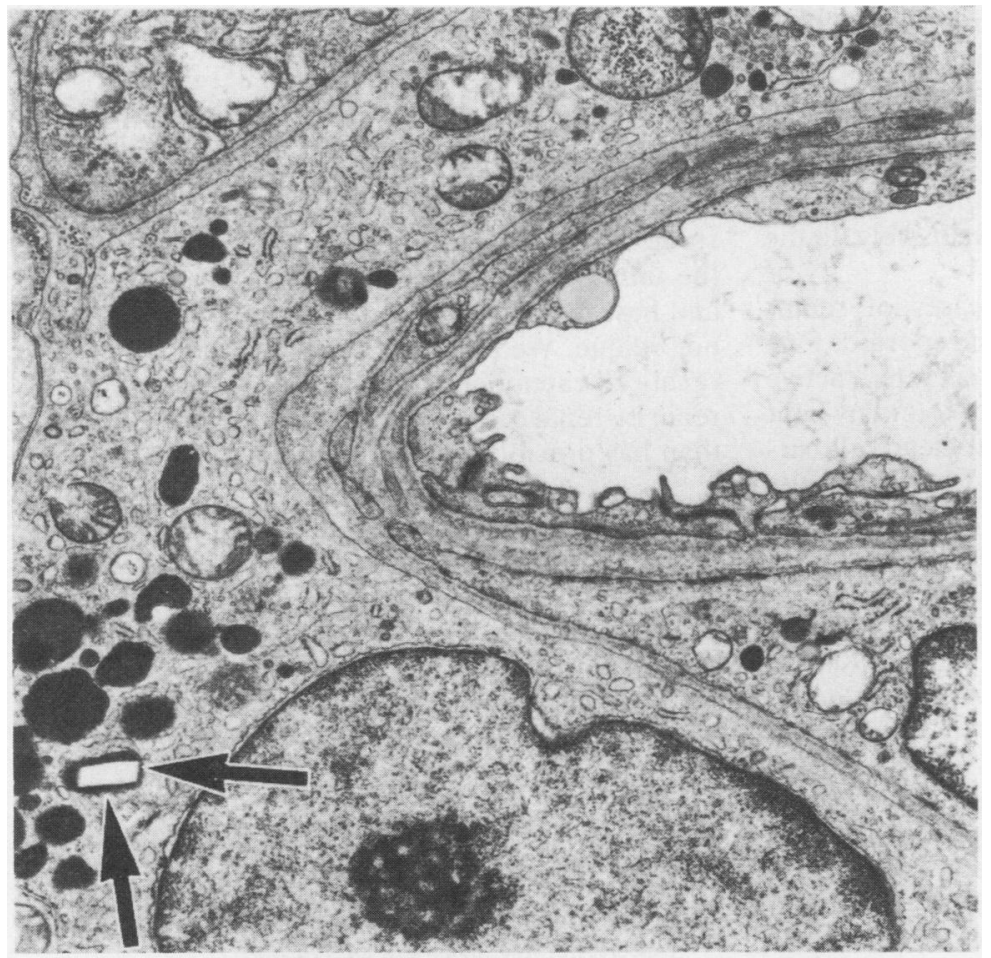

Fig. 6 Electron micrograph showing a granular cell with a cytoplasmic process wrapped round a capillary external to the basal lamina. One of the membrane-bound granules has a crystalline inclusion (arrow) which has been removed during processing $\times 13275$.

cytoplasmic organelles. The Golgi apparatus was well formed and the smooth endoplasmic reticulum and small scattered cysternae of rough endoplasmic reticulum were easily found. Mitochondria were present in moderate numbers. Numerous granules were present scattered throughout the cytoplasm. These were membrane-bound, irregular in shape and varied in size (0.1-0.6 $\mu \mathrm{m})$. A few granules contained spaces where crystalline material had been removed during processing. Unfortunately, no protogranules and no residual crystalline material could be identified. The granules had a mainly granular substructure and were consistent with the variable morphology of renin granules. Occasional lysosomes were admixed with the population of granules. Occasional small lipid droplets were present but glycogen was sparse or absent. No myofilaments were seen.

The nuclei were predominantly oval in shape with occasional indentations. There was clumped peripheral heterochromatin and the nucleoli were large and usually single. Cell-to-cell borders with the adjacent tumour cells were long and straight with no obvious cell-to-cell specialised junctions. Where there were no adjacent cells in the immediate proximity, the cells showed blunt cytoplasmic projections.

By comparison, the renal tumour cells showed abundant glycogen and fat droplets. Cytoplasmic organelles were usually scanty in amount and confined to one area of the cell cytoplasm (Fig. 5). Occasional lysosomes were seen, but there were no granules similar to those in the granular cells just described. The electron microscopic features were typical of a clear cell carcinoma. No cells intermediate in morphology between the typical renal carcinoma cells and perivascular stromal cells could be identified.

Mast cells were detected and showed the typical morphology of their cytoplasmic granules. These were distinct from the perivascular renin-containing granular cells although the two types of cell were occasionally found in juxtaposition.

\section{Discussion}

Previous studies with this antibody have amply demonstrated its specificity and reliability in staining renin in tissue sections by both immunofluorescence and immunoperoxidase techniques. ${ }^{7}$ Included in the specificity tests was the abolition of the staining by prior incubation of the antibody with pure human renin. We have shown that this antibody in a dilution of $1 / 10000$ completely precipitated $96 \mu \mathrm{U} / \mathrm{ml}$ of active renin and $86 \mu \mathrm{U} / \mathrm{ml}$ of inactive renin from extracts of the patient's kidney and tumour respect- 
ively (BJ Leckie, unpublished observations, 1982). Other workers have also shown that a similar antibody to pure human renin also binds to inactive human renin in vitro. ${ }^{11}$ It is therefore not surprising that the antibody used here bound to the renin in this tumour which biochemical studies have previously shown was mainly, but not exclusively, in the inactive form. ${ }^{4}$

To our knowledge, two other cases of reninsecreting renal carcinoma have been reported. One was an acidophilic tumour which secreted active renin, ${ }^{12}$ but in which no granules were found by light microscopy. The other was a typical clear cell carcinoma similar to the case described here..$^{13}$ In the latter case, electron microscopy showed granules within the clear cells of the tumour. These had a morphology consistent with renin granules.

In the case presented here the immunoperoxidase technique clearly identified the renin-containing cells as a population of small perivascular cells. These cells contained granules with morphological characterisics compatible with renin granules. They differed in their immunocytochemical and ultrastructural features from macrophages which might have ingested products of renin secretion by tumour cells. They were also clearly distinguishable from mast cells. The ultrastructural and immunocytochemical findings presented here provides strong evidence that these granular cells were the site of synthesis and storage of the renin secreted by the tumour.

There seem to be two main possibilities as to their histogenesis; firstly, it is possible that these cells are renin-secreting cells which have grown into the tumour along with the blood vessels from adjacent kidney and have colonised the tumour. Blood vessels are known to grow into tumours from the host tissue, presumably influenced by growth factors secreted by the tumour. ${ }^{14}$ Secondly, they may represent differentiation of tumour cells. Against the second possibility is the fact that the perivascular granular cells are clearly distinguishable from the clear cells of the tumour by light microscopy, electron microscopy and immunocytochemistry. While larger forms were occasionally seen, no definite transitions between the granular cells and the tumour cells could be identified. However differentiation of tumour cells remains a possibility which is difficult to exclude. The histogenesis of these cells may be resolved by careful study of further cases.

The renin secreted by this tumour has been shown to be biologically inactive. ${ }^{4}$ It is probable, but not certain, that inactive renin is a biological precursor, or prohormone, of the active enzyme. ${ }^{2}$ If true, this tumour would be analogous to those other tumours secreting prohormones such as proinsulin and proadrenocorticotrophic hormone. ${ }^{15}$ These prohormones secreted by tumours are often without clinical effects and it has been shown that a systematic measurement of hormones in plasma and in tumour can detect hormone production and secretion in the absence of any clinical manifestations. ${ }^{1}$ We have studied a small series of renal cell carcinomas with the immunocytochemical technique described here and have confirmed that the case we now report is not unique. We found immunoreactive renin in $8 / 17$ renal cell carcinomas. Thus the secretion of inactive renin by renal cell carcinoma may well be commoner than has previously been realised.

We are grateful for the generous gift of the antibody to pure human renin to Professor P Corvol and Professor J Menard of Unite INSERM u 36-17, rue du Fer à Moulin-75005 Paris. We acknowledge with gratitude the technical expertise of $\mathrm{Mr} \mathrm{J}$ Stewart who established the immunocytochemical technique, and Mr T Downie who provided the electron micrographs.

\section{References}

${ }^{1}$ Odell WD, Wolfsen AR. Humoral syndromes associated with cancer. Ann Rev Med 1978;29:379-406.

${ }^{2}$ Leckie BJ, McConnell A, Grant J, Morton JJ, Tree M, Brown JJ. An inactive renin in human plasma. Circ Res 1977;40: (suppl 1) 46-51.

${ }^{3}$ Day RP, Luetscher JA. Big renin, a possible prohormone in kidney and plasma in a patient with Wilms' tumour.J Clin Endocrinol Metab 1974;38:923-6.

${ }^{4}$ Leckie Brenda, Brown JJ, Fraser R, Kyle K, Lever AF, Morton $\mathrm{JJ}$, Robertson JIS. A renal carcinoma secreting inactive renin. Clin Sci Mol Med 1978;55:159S-161S.

${ }^{s}$ Galen FX, Devaux C, Guyenne TT, Menard J, Corvol P. Multiple forms of human renin: purification and characterisation. J Biol Chem 1979;254:4848-55.

- Galen FX, Guyenne TT, Devaux C, Auzan C, Corvol P, Menard J. Direct radioimmunoassay of human renin. J Clin Endocrinol Metab 1979;48:1041-5.

${ }^{7}$ Camilleri JP, Phat, Vuong N, Bariety J, Corvol P, Menard J. Use of a specific antiserum for renin detection in human kidney. J Histochem Cytochem 1980;28:1343-6.

${ }^{8}$ Phat Vuong N, Camilleri JP, Bariety J, Galtier M, Baviera E, Corvol P, Menard J. Immunohistochemical characterisation of renin-containing cells in the human juxtaglomerular apparatus during embryonal and fetal development. Lab Invest 1981;45:387-90.

9 Amat D, Camilleri JP, Vuong NP, Bariety J, Corval P, Menard J. Renin localization in segmental renal hypoplasia. Virchows Arch (Pathol Anat) 1981;390:193-204.

${ }^{10}$ Graham RC, Karnovsky MJ. The early stages of absorption of injected horseradish peroxidase in the proximal tubules of mouse kidney: ultrastructural cytochemistry by a new technique. J Histochem Cytochém 1966;14:291-302.

"Yokosawa H, Yokosawa N, Inagami T. Specific antibody to human renal renin and its cross-reactivity with inactive human plasma prorenin. Proc Soc Exp Biol Med 1980;164:466-70.

${ }^{12}$ Lebel M, Talbot J, Grose J, Morin J. Adenocarcinoma of the kidney and hypertension: report of two cases with special emphasis on renin. J Urol 1977;118:923-7. 
${ }^{13}$ Hollifield JW, Page DL, Smith C, Michelakis AM, Staab E, Rhamy R. Renin-secreting clear cell carcinoma of the kidney. Arch Intern Med 1975;135:859-64.

${ }^{14}$ Folkman J, Merler E, Abernathy C, Williams G. Isolation of a tumour factor responsible for angiogenesis. $J$ Exp Med 1971;133:275-88.

is Kameya T, Shimosata Y, Abe K, Takenchi T. Morphologic and functional aspects of hormone-producing tumours. In: Som- mers SC, Rosen PP, eds. Pathology Annual. New York: Appleton-Century Crofts, 1980:351-86.

Requests for reprints to Dr GBM Lindop, Pathology Department, Western Infirmary, Glasgow G11 6NT, Scotland 